\title{
Study of serum transforming growth factor-beta 1 (TGF-ß1) levels in type 2 diabetes mellitus patients with nephropathy.
}

\author{
Avanish Shukla ${ }^{1}$, Pawan Kumar Kare ${ }^{2 *}$, Basu Dev Banerjee ${ }^{2}$, Om Prakash Kalra ${ }^{1}$, Alpana Raizada ${ }^{1}$, \\ Ashok Kumar Tripathi \\ ${ }^{1}$ Department of Medicine, University College of Medical Sciences and Guru Teg Bahadur Hospital, Dilshad Garden, \\ Delhi, India \\ ${ }^{2}$ Department of Biochemistry, University College of Medical Sciences and Guru Teg Bahadur Hospital, Dilshad \\ Garden, Delhi, India
}

\begin{abstract}
Background: Diabetic nephropathy (DN) is a major micro-vascular complication of diabetes mellitus (DM) and it is the leading cause of end stage renal disease (ESRD) worldwide. The present study was carried out to estimate the serum TGF- $\beta 1$ levels in T2DM patients with nephropathy.

Methodology: All study subjects $(n=75)$ were enrolled in 3 groups. Group 1: $(n=25)$ healthy controls, group 2: (n=25) T2DM patients without nephropathy, group 3: $(n=25)$ T2DM patients with nephropathy. Patients were recruited from diabetic and nephrology clinic at University College of Medical Sciences and Guru Teg Bahadur Hospital, Delhi, India. Morning spot urine samples were collected for urine albumin and creatinine test. Serum and urine creatinine were estimated by alkaline picrate Jaffe's kinetic method. Urine albumin was estimated by turbidometric method. Albumin/creatinine ratio (ACR) was expressed in mg/g creatinine. Serum TGF- $\beta 1$ level was measured by ELISA kit.

Results: A statistically significant difference was found in the levels of urinary ACR between the study groups I and III, II and III ( $p=0.000$ ), but no statistically significant difference was found between groups I and II ( $p=0.460)$. There was a statistically significant difference observed in the serum TGF- $\beta 1$ levels between the study groups I and II, I and III and II and III (p=0.000). Serum TGF- $\beta 1$ showed significant positive correlation with $\mathrm{HbA1c}$, fasting plasma glucose, post prandial plasma glucose, serum creatinine and urinary ACR. However, a negative correlation was found between serum TGF- $\beta 1$ and eGFR.

Conclusions: Serum TGF- $\beta 1$ levels were found higher in patients with T2DM and were significantly elevated in T2DM patients with nephropathy. Serum TGF- $\beta 1$ levels in diabetic patients were dependent on the glycemic control and degree of renal dysfunction however, its levels were not dependent on the duration of diabetes.
\end{abstract}

Keywords: Type 2 diabetes mellitus, TGF- $\beta 1$, Diabetic nephropathy, Albumin/creatinine ratio.

List of Abbreviations:

T2DM: Type 2 Diabetes Mellitus; DN: Diabetic Nephropathy;

ACR: Albumin/Creatinine Ratio.

Accepted on August 23, 2018

\section{Introduction}

Diabetic nephropathy (DN) is characterized by a progressive increase in urine albumin excretion, and fall in glomerular filtration rate (GFR) which leads to end stage renal disease (ESRD) [1]. DN accounts for $31.3 \%$ of all cases of chronic kidney disease (CKD) in India [2]. Renal hypertrophy, deposition of extracellular matrix (ECM) in mesangial cells, thickening of glomerular basement membrane, and glomerulosclerosis are major renal functional changes associated with progressive glomerular capillary occlusion, albuminuria and a progressive fall in GFR [3].

Transforming growth factor beta (TGF- $\beta$ ) is a multifunctional cytokine which plays an important role in the development of nephropathy in type 2 diabetes mellitus patients. The TGF- $\beta$ family consists of multifunctional molecules which are associated with cell proliferation, differentiation, migration and tissue remodelling processes [4]. Of these, TGF- $\beta 1$ is known as the most fibrogenic molecule which stimulates the transcription of various genes in renal cells including 
mesangial, endothelial and tubular cells. The increase in synthesis and decrease in turnover of these proteins results in net accumulation of extracellular matrix. Accumulation of extracellular matrix components such as fibronectin, collagen types I, III and IV enhances the progression of glomerulosclerosis and tubulointerstitial fibrosis [5]. As DN is largely thought to be due to dysregulated ECM production and increased production of TGF- $\beta$ induces synthesis and accumulation of renal extracellular matrix proteins such as fibronectin and collagen that are actively involved in renal fibrosis. Therefore, TGF- $\beta 1$ may play an important role in the pathogenesis of DN [6].

There are very few studies demonstrate the levels of TGF- $\beta 1$ in type 2 diabetes mellitus patients with nephropathy in Indian population [7]. Therefore, the present study was undertaken to estimate the serum TGF- $\beta 1$ levels in T2DM patients with nephropathy.

\section{Subjects and Methods}

\section{Study design}

This study was a cross-sectional study. Total subjects $(n=75)$ were recruited during the period of December 2013-April 2015. The subjects were then divided in three groups; group 1: $(n=25)$ healthy controls, group 2: $(n=25)$ T2DM patients without nephropathy, group 3: $(n=25)$ T2DM patients with nephropathy (Figure 1). Groups 2 and 3 subjects were recruited from diabetic and nephrology clinic at University College of Medical Sciences and Guru Teg Bahadur Hospital, Delhi, India. Age and sex matched healthy subjects as controls (group 1) were also recruited. Diagnosis of T2DM was based upon American Diabetes Association (ADA) 2011 guidelines [8]. $\mathrm{DN}$ was diagnosed on the basis of persistent micro-albuminuria (ACR 30-299 mg/g creatinine) or overt albuminuria (ACR $\geq$ $300 \mathrm{mg} / \mathrm{g}$ creatinine) on two separate occasions (6 w apart) and presence of diabetic retinopathy on the basis of National Kidney Foundation (NKF) 2012 guidelines [9]. Patient's fundus examination was done by direct ophthalmoscopy to look for evidence of diabetic retinopathy. The study was approved by Institutional Ethics Committee-Human Research (IEC-HR) of University College of Medical Sciences and Guru Teg Bahadur Hospital, Delhi and written informed consent for participation in this study was taken from all participants.

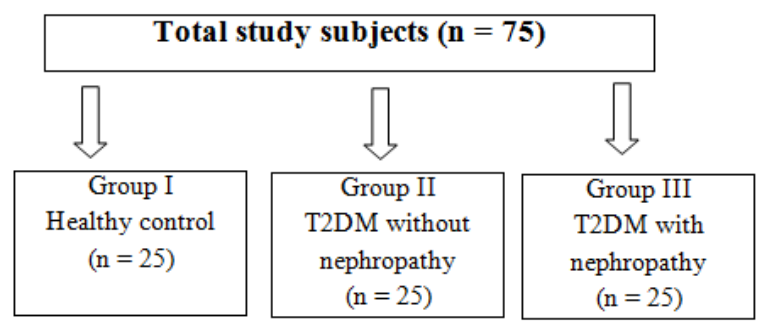

Figure 1. Flow chart of the study design.

\section{Inclusion and exclusion criteria}

Inclusion criteria: Group 1 (Healthy controls): Age 30 to 65 $\mathrm{y}$, normotensive and normoglycemia.

Group 2 (T2DM patients without nephropathy): Presence of T2DM.

Group 3 (T2DM patients with nephropathy): Presence of DM, patients having evidence of diabetic retinopathy and evidence of microalbuminuria or overt proteinuria.

Groups 2 and 3 subjects were aged between 30 to $65 \mathrm{y}$ with the duration of diabetes $\geq 5 \mathrm{y}$.

Exclusion criteria: Patients with DM due to type 1 or secondary cause, presence of urinary or systemic infection, patients taking aspirin and systemic steroids were excluded from the study.

\section{Estimation of biochemical parameters}

Blood sample $(3 \mathrm{ml})$ was collected for biochemical analysis. Blood was centrifuged at $1000 \mathrm{~g}$ for $15 \mathrm{~min}$ for plasma and serum separation. The plasma glucose, glycated hemoglobin (HbA1c), blood urea and hemoglobin were estimated in hospital laboratory at UCMS and GTB Hospital, Delhi.

\section{Estimation of urinary albumin/creatinine ratio (ACR) and glomerular filtration rate (GFR)}

Morning spot urine samples were collected for urine albumin and urine creatinine test. Serum and urine creatinine were carried out by alkaline picrate Jaffe's kinetic method [10]. Urine albumin was estimated by turbidometric method by using nephelometer (Nephstar ${ }^{\circledR}$, Goldsite Diagnostics). The sensitivity limit is $10 \mathrm{mg} / \mathrm{L}$. Albumin/creatinine ratio was expressed in $\mathrm{mg} / \mathrm{g}$ creatinine. Estimated glomerular filtration rate (eGFR) was calculated by Modification of Diet in Renal Disease (MDRD) equation [11].

\section{Estimation of serum TGF $\beta 1$ level}

Serum TGF- $\beta 1$ levels were measured by commercially available ELISA kit. All the stored samples for the estimation of TGF- $\beta 1$ levels were determined within a month.

\section{Statistical analysis}

Statistical analysis was carried out by SPSS version 20.0. Data were expressed as mean $\pm \mathrm{SD}$, median (IQR) or percentage (\%) as applicable. Mean values of all demographic and biochemical parameters in all three groups were compared by one-way ANOVA followed by post hoc Tukey's test or Kruskal-Wallis test used for not normally distributed data. Multivariate analysis was done using Bonferroni adjustment. Correlation was analysed by using Pearson's correlation coefficient. $p<0.05$ was considered as the level of significance. 
Study of serum transforming growth factor-beta 1 (TGF- $\beta 1)$ levels in type 2 diabetes mellitus patients with nephropathy

\section{Results}

\section{Demographic characteristics of study subjects}

The demographic characteristics of the study subjects are listed in Table 1. Among the subjects thirty eight (50.66\%) were males and thirty seven $(49.33 \%)$ were females. Mean duration of diabetes mellitus was $6.29 \pm 3.94 \mathrm{y}$ in group II and $9.72 \pm$
$3.18 \mathrm{y}$ in group III. There was a statistically significant difference in the duration of diabetes between groups II and III $(p=0.001)$. The mean age of subjects in groups I-III were 47.56 $\pm 7.96 \mathrm{y}, 48.88 \pm 7.73 \mathrm{y}$ and $47.84 \pm 9.22 \mathrm{y}$ respectively. There was no statistically significant difference in systolic blood pressures (SBP) and diastolic blood pressure (DBP) between the groups. However, statistically significant difference was found in hemoglobin levels between groups I and III ( $\mathrm{p}=0.02)$.

Table 1. Demographic characteristics of the study subjects.

\begin{tabular}{|c|c|c|c|c|c|}
\hline Characteristics & Group I $(n=25)$ & Group II $(n=25)$ & Group III $(n=25)$ & ${ }^{*} \mathrm{p}$ value & ${ }^{\#} \mathbf{p}$ value \\
\hline Male/Female & $13 / 12$ & $13 / 12$ & $13 / 12$ & & \\
\hline \multirow[t]{2}{*}{ Duration of diabetes $(y)$} & - & $6.29 \pm 3.94$ & $9.72 \pm 3.18$ & 0.001 & $\mathrm{II}$ and $\mathrm{II}=0.001$ \\
\hline & & & & & $I$ and $I I=0.840$ \\
\hline \multirow[t]{3}{*}{ Age (y) } & $47.56 \pm 7.96$ & $48.88 \pm 7.73$ & $47.84 \pm 9.22$ & 0.39 & $\mid$ and || $\mid=0.991$ \\
\hline & & & & & $\mathrm{II}$ and $\mathrm{II}=0.892$ \\
\hline & & & & & I and II=0.062 \\
\hline \multirow[t]{3}{*}{$\mathrm{SBP}(\mathrm{mmHg})$} & $120.20 \pm 1.65$ & $126.72 \pm 13.02$ & $125.541 \pm 11.43$ & 0.078 & I and $\mid \mathrm{II}=0.477$ \\
\hline & & & & & $\mathrm{II}$ and $\mathrm{III}=0.512$ \\
\hline & & & & & $I$ and $\mid I=0.902$ \\
\hline \multirow[t]{3}{*}{$\mathrm{DBP}(\mathrm{mmHg})$} & $79.04 \pm 1.06$ & $78.08 \pm 7.53$ & $74.04 \pm 11.22$ & 0.063 & $\mid$ and || $\mid=0.068$ \\
\hline & & & & & $\mathrm{II}$ and $\mathrm{II}=0.169$ \\
\hline & & & & & I and II =0.933 \\
\hline \multirow[t]{2}{*}{ Hemoglobin (g/dl) } & $12.66 \pm 1.66$ & $12.50 \pm 1.77$ & $11.36 \pm 1.58$ & 0.015 & $\mid$ and || $\mid=0.020$ \\
\hline & & & & & $\mathrm{II}$ and $\mathrm{II}=0.050$ \\
\hline
\end{tabular}

Data are expressed as mean $\pm \mathrm{SD}$, $\mathrm{p}$ value is significant at $\mathrm{p}<0.05$; "One way ANOVA/Kruskal Wallis test; \#Tukey's test/Boneferroni adjustment. SBP: Systolic Blood Pressure; DBP: Diastolic Blood Pressure.

\section{Biochemical parameters of the study subjects}

The biochemical investigations of the study subjects are listed in Table 2. A significant difference was observed for HbA1c values between groups II and III $(p=0.001)$. Patients in group III had significantly higher blood urea and serum creatinine levels when compared with groups I or group II. No significant difference was found for blood urea and serum creatinine levels when group II was compared with group I. The median value of eGFR found in groups I-III was 90.90 (70.47-100.48 $\mathrm{ml} / \mathrm{min}), 77.58(68.03-94.74 \mathrm{ml} / \mathrm{min})$ and 46.94 (36.94-58.55 $\mathrm{ml} / \mathrm{min}$ ), respectively. The median value of urinary ACR found in groups I-III was $10.40(8.0415 .68 \mathrm{mg} / \mathrm{g}), 15.98$ (10.00-19.12 $\mathrm{mg} / \mathrm{g})$ and $292.03 \quad(114.8-498.24 \mathrm{mg} / \mathrm{g})$, respectively. Statistically significant difference was found in the levels of urinary ACR between the study groups I and III, II and III $(p=0.000)$, however, no statistically significant difference was observed between groups I and II $(\mathrm{p}=0.46)$.

Table 2. Biochemical characteristics of study subjects.

\begin{tabular}{|c|c|c|c|c|c|}
\hline Parameters & Group I $(n=25)$ & Group II $(n=25)$ & Group III $(n=25)$ & *p value & ${ }^{\#}$ p value \\
\hline \multirow{3}{*}{ Fasting plasma glucose (mg/dL) } & \multirow{3}{*}{$84.96 \pm 6.89$} & \multirow{3}{*}{$149.72 \pm 29.7$} & \multirow{3}{*}{$176.96 \pm 95.54$} & \multirow{3}{*}{0.000} & $\mathrm{I}$ and $\mathrm{II}=0.001$ \\
\hline & & & & & $\mathrm{I}$ and $\mathrm{III}=0.000$ \\
\hline & & & & & $\mathrm{II}$ and $\mathrm{II}=0.226$ \\
\hline \multirow[b]{2}{*}{ Post-prandial plasma glucose (mg/dL) } & \multirow[b]{2}{*}{$107.16 \pm 9.52$} & \multirow[b]{2}{*}{$213.64 \pm 64.5$} & \multirow[b]{2}{*}{$252.28 \pm 97.77$} & \multirow[b]{2}{*}{0.000} & $\mathrm{I}$ and $\mathrm{II}=0.000$ \\
\hline & & & & & $\mathrm{I}$ and $\mathrm{II}=0.000$ \\
\hline
\end{tabular}




\begin{tabular}{|c|c|c|c|c|c|}
\hline & & & & & \\
\hline & & & & & $\mathrm{II}$ and $\mathrm{II}=0.283$ \\
\hline $\mathrm{HbA} 1 \mathrm{c}(\%)$ & - & $7.71 \pm 0.95$ & $10.36 \pm 1.80$ & 0.001 & $\mathrm{II}$ and $\mathrm{II}=0.001$ \\
\hline & & & & & I and II=0.999 \\
\hline Blood urea $(\mathrm{mg} / \mathrm{dL})$ & $23.56 \pm 6.04$ & $23.66 \pm 5.13$ & $50.12 \pm 15.89$ & 0.000 & $\mathrm{I}$ and $\mathrm{III}=0.000$ \\
\hline & & & & & $\mathrm{II}$ and $\mathrm{II}=0.000$ \\
\hline & & & & & $\mathrm{I}$ and $\mathrm{II}=0.877$ \\
\hline Serum creatinine (mg/dL) & $0.85 \pm 0.12$ & $0.88 \pm 0.17$ & $1.40 \pm 0.28$ & 0.000 & $I$ and $I I I=0.000$ \\
\hline & & & & & $\mathrm{II}$ and $\mathrm{II}=0.000$ \\
\hline & & & & & $I$ and $I I=1.000$ \\
\hline$\$$ eGFR (ml/min/1.732) & $90.9(70-100.48)$ & $77.58(68.03-94.74)$ & $46.94(36.94-58.55)$ & 0.000 & $\mathrm{I}$ and $\mathrm{II}=0.000$ \\
\hline & & & & & $\mathrm{II}$ and $\mathrm{III}=0.000$ \\
\hline & & & & & $I$ and $I I=0.460$ \\
\hline \$Urinary ACR (mg/g creatinine) & $10.4(8.04-15.68)$ & $15.98(10.00-19.12)$ & $292.03(114.8-498.24)$ & 0.000 & $\mathrm{I}$ and $\mathrm{II}=0.000$ \\
\hline & & & & & $\mathrm{II}$ and $\mathrm{II}=0.000$ \\
\hline
\end{tabular}

Data is expressed as mean $\pm \mathrm{SD}$, ${ }^{\$}$ Median (IQR), $p$ value is significant at $p<0.05$; ${ }^{*}$ One way ANOVA/Kruskal Wallis Test; ${ }^{\# T u k e y ' s ~ t e s t / B o n e f e r r o n i ~ a d j u s t m e n t . ~ e G F R: ~}$ Estimated Glomerular Filtration Rate; ACR: Albumin/Creatinine Ratio.

\section{Serum TGF-ק1 levels in the study subjects}

Serum TGF- $\beta 1$ levels in the study subjects are presented in Table 3 . There was a statistically significant difference found in the serum TGF- $\beta 1$ levels between all the 3 groups ( $p$ value $=0.000$ ). However, TGF- $\beta 1$ levels were higher in T2DM with nephropathy patients (group III) as compared to T2DM without nephropathy patients (group II). This indicates association of TGF- $\beta 1$ levels with the micro-vascular complication (diabetic nephropathy) of diabetes mellitus.

Table 3. Serum TGF- $\beta 1$ levels in study subjects.

\begin{tabular}{|c|c|c|c|c|c|}
\hline Parameter & Group I ( $n=25)$ & Group II $(n=25)$ & Group III (n=25) & *p value & ${ }^{\#} \mathbf{p}$ value \\
\hline \multirow{3}{*}{ Serum TGF- $\beta 1(p g / m L)$} & \multirow{3}{*}{$15.34(11.17-22.00)$} & \multirow{3}{*}{$43.54(39.32-52.79)$} & \multirow{3}{*}{$89.34(62.08-111.28)$} & \multirow{3}{*}{0.000} & $I$ and $I I=0.000$ \\
\hline & & & & & $\mathrm{I}$ and $\mathrm{II}=0.000$ \\
\hline & & & & & $\|$ and $\| I=0.005$ \\
\hline
\end{tabular}

Data is presented as Median (IQR), $p$ value is significant at $p<0.05$. "Kruskal Wallis test; \#Boneferroni adjustment.

Table 4. Correlation between serum TGF- $\beta 1$ and other study variables.

\begin{tabular}{lll}
\hline Variables & Correlation coefficient $(\mathbf{r})$ & p value \\
\hline Duration of diabetes $(\mathrm{y})$ & 0.219 & 0.126 \\
\hline $\mathrm{HbA} 1 \mathrm{c}(\%)$ & 0.520 & 0.000 \\
\hline Fasting plasma glucose $(\mathrm{mg} / \mathrm{dL})$ & 0.637 & 0.000 \\
\hline Post-prandial plasma glucose $(\mathrm{mg} / \mathrm{dL})$ & 0.702 & 0.000 \\
\hline Serum creatinine $(\mathrm{mg} / \mathrm{dL})$ & 0.640 & 0.000 \\
\hline eGFR (ml/min/1.732) & -0.590 & 0.000 \\
\hline Urinary ACR (mg/g creatinine) & 0.856 & 0.000 \\
\hline p<0.05; significance level. & &
\end{tabular}

$\mathrm{p}<0.05$; significance level.

\section{Correlation analysis of serum TGF-B1 levels with study variables}

The correlation analysis of serum TGF- $\beta 1$ and study variables such as duration of diabetes, HbAlc, fasting plasma glucose, post prandial plasma glucose, serum creatinine, eGFR and urinary ACR are shown in Table 4. Serum TGF- $\beta 1$ levels showed significant positive correlation with $\mathrm{HbA} 1 \mathrm{c}(\mathrm{r}=0.520$, $\mathrm{p}=0.000)$, fasting plasma glucose $(\mathrm{r}=0.637, \mathrm{p}=0.000)$, post prandial plasma glucose $(\mathrm{r}=0.702, \mathrm{p}=0.000)$, serum creatinine $(\mathrm{r}=0.640, \mathrm{p}=0.000)$, and urinary ACR $(\mathrm{r}=0.856, \mathrm{p}=0.000)$. However, Serum TGF- $\beta 1$ levels showed non-significant positive correlation with duration of diabetes $(\mathrm{r}=0.219$, $\mathrm{p}=0.126$ ). A significant negative correlation was found between TGF- $\beta 1$ and eGFR $(r=-590, p=0.000)$. 


\section{Discussion}

Diabetic nephropathy (DN) is a major public health concern worldwide. Patients with DN are at high risk for progression to the end stage renal disease (ESRD). Progression to ESRD or other adverse outcomes could be prevented or delayed through early detection and treatment of DN. Hence there is a need to identify the development of DN at an early stage so that its progression can be prevented. Urine albumin to creatinine ratio (UACR) is the commonly used method to predict microalbuminuria in diabetes mellitus at an early stage. Microalbuminuria is associated with an increased rate of progression of diabetic kidney disease in patients with both type 1 and type 2 diabetes [12]. However, some reports have shown that microalbuminuria (30-300 $\mathrm{mg}$ albumin/g creatinine) is not a specific marker for development of diabetic nephropathy in type 2 diabetes at early stage [13]. Therefore, it is needed to identify new markers which can detect nephropathy at an earlier stage. Neutophil gelatinase-associated lipocalin (NGAL), urinary liver-type fatty acid binding protein (LFABP), kidney injury molecule-1 (KIM-1), interleukin-18 (IL-18), TGF- $\beta 1$ and various others are being increasingly studied as newer markers for development of nephropathy [14].

In the present study, serum TGF- $\beta 1$ levels were estimated in healthy control (group I), T2DM (group II) and T2DM with nephropathy (group III) subjects by ELISA method. The present study has shown statistically significant difference $(p$ value $=0.000$ ) in the serum levels of TGF- $\beta 1$ between the study groups I-III. Serum TGF- $\beta 1$ levels were found significantly higher in diabetic nephropathy patients (group III). These results are supported by Shaker et al. [15]. Yaqiu et al. and Shaker et al. indicated that TGF- $\beta 1$ levels increased in diabetic patients in accordance with various stages of albuminuria. Therefore, the serum concentration of TGF- $\beta 1$ levels increases in the early stages of diabetic nephropathy and keep elevating with the progression of DN $[15,16]$. Vishwanathan et al. have also demonstrated significantly elevated TGF- $\beta 1$ levels in South Indian type 2 diabetic patients when compared with the non-diabetic subjects. [7]. Ibrahim et al. have also reported significantly elevated serum TGF- $\beta 1$ levels in microalbuminuric and overt proteinuric diabetic patients as compared to healthy controls [17].

In the present study, duration of diabetes mellitus was higher in group III as compare to group II. This is in accordance to previous study of Inassi et al. who showed that impairment of renal functions increases with the duration of diabetes [18]. Alrawahi et al. have found that duration of diabetes mellitus is an important risk factor for development and progression of nephropathy in type 2 DM patients [19]. However, TGF- $\beta 1$ levels were not dependent on the duration of diabetes in the present study. There are some reports also indicating weak or no correlation of TGF- $\beta 1$ with the duration of diabetes $[15,16]$.

A correlation study of serum TGF- $\beta 1$ levels with HbA1c, fasting blood glucose and post prandial blood glucose were carried out in this study. We also observed a positive and significant correlation of serum TGF- $\beta 1$ level with $\mathrm{HbAlc}$, fasting blood glucose and post prandial blood glucose. Shaker et al. also reported a positive significant correlation between serum TGF- $\beta 1$ and both glucose concentration and $\mathrm{HbAlc}$ [15]. Ibrahim et al. have also found that serum TGF- $\beta 1$ was significantly increased in patients with poor glycemic control with variable degree of renal dysfunction as compared to those with good glycemic control and comparable degree of renal dysfunction. These finding conform the direct link between hyperglycemia and activation of TGF- $\beta 1$. It is known that glucose stimulates de novo synthesis of diacylglycerol (DAG) and activated DAG then leads to activation of protein kinase $\mathrm{C}$ (PKC) which increases TGF- $\beta 1$ synthesis in mesangial cell and tubular cell [17].

In the present study, a significant positive correlation was found between serum TGF- $\beta 1$ levels and serum creatinine. This is in accordance with various studies, where active TGF$\beta 1$ concentrations were correlated with serum creatinine $[16,20]$. However, we observed negative correlation between serum TGF- $\beta 1$ level and eGFR, which is statistically significant. We also found significant positive correlation between serum level of TGF- $\beta 1$ and urinary ACR. This is similar with the previous study by Shaker et al. who reported that urinary and serum TGF- $\beta 1$ showed strong positive correlation with urinary ACR in diabetic nephropathy patients [15]. Another report by Ibrahim et al. has shown a significant positive correlation between serum TGF- $\beta 1$ level and $24 \mathrm{~h}$ urinary protein excretion, which was equivalent to spot urinary ACR [16]. Similarly, Revora et al. have also demonstrated the significant positive correlation between the TGF- $\beta 1$ in urine and proteinuria ( $24 \mathrm{~h}$ urinary protein) in patients with type 2 diabetes [3].

\section{Limitation of the Study}

In the present study sample size was small. Further studies with large sample size are needed to validate our results. Other factors leading to glomerular injury were not studied which can falsely elevate the serum TGF- $\beta 1$ levels.

\section{Conclusions}

Serum TGF- $\beta 1$ is considered to be potential biomarker for identifying the patients of type 2 diabetes mellitus at risk for developing nephropathy.

\section{Competing Interest}

The author (s) declares that there are no competing interests.

\section{Consent}

All authors declare that written informed consent was obtained from the participants.

\section{Ethical Approval}

All authors hereby declare that all experiments have been examined and approved by the appropriate ethics committee and have therefore been performed in accordance with the 
ethical standards laid down in the 1964 Declaration of Helsinki.

\section{References}

1. Obineche EN, Adem A. Update in diabetic nephropathy. Int J Diabetes Metab 2005; 13: 1-9.

2. Rajapurkar MM, John GT, Kirpalani AL, Abraham G, Agarwal SK, Almeida AF, Gang S, Gupta A, Modi G, Pahari D, Pisharody R, Prakash J, Raman A, Rana DS, Sharma RK, Sahoo RN, Sakhuja V, Tatapudi RR, Jha V. What do we know about chronic kidney disease in India: first report of the Indian CKD registry. BMC Nephrol 2012; 13: 10.

3. Rivarola EW, Moyses-Neto M, Dantas M, Da-Silva CG, Volpini R, Coimbra TM. Transforming growth factor beta activity in urine of patients with type 2 diabetes and diabetic nephropathy. Braz J Med Biol Res 1999; 32: 1525-1528.

4. Le Y, Yu X, Ruan L. The immunopharmacological properties of transforming growth factor beta. Int Immunopharmacol 2005; 5: 1771-1782.

5. Fukuda N, Tahira Y, Matsuda H, Matsumoto K. Transforming growth factor-beta as a treatment target in renal diseases. J Nephrol 2009; 22: 708-715.

6. Sharma K, Ziyadeh FN, Alzahabi B, McGowan TA, Kapoor S, Kurnik BR, Kurnik PB, Weisberg LS. Increased renal production of transforming growth factorbetal in patients with type II diabetes. Diabetes 1997; 46: 854-859.

7. Viswanathan V, Snehalatha C, Nair MB, Kumutha R, Ramachandran A. Levels of transforming growth factor beta 1 in south Indian type 2 diabetic subjects. Diabetes Metab Res Rev 2005; 21: 276-280.

8. American Diabetes Association. Standards of medical care in diabetes. Diabetes Care 2011; 34: 11-61.

9. National Kidney Foundation. KDOQI Clinical Practice Guideline for Diabetes and CKD: 2012 update. Am J Kidney Dis 2012; 60: 850-886.

10. Bowers LD, Wong ET. Kinetic serum creatinine assays. II. A critical evaluation and review. Clin Chem 1980; 26: 555-561.

11. Levey AS, Coresh J, Greene T, Stevens LA, Zhang YL. Using standardized serum creatinine values in the modification of diet in renal disease study equation for estimating glomerular filtration rate. Ann Intern Med 2006; 145: 247-254.

12. Mattix HJ, HSU CY, Shaykevich S, Curhan G. Use of the albumin/creatinine ratio to detect microalbuminuria: implications of sex and race. J Am Soc Nephrol 2002; 13: 1034-1037.

13. Bhensdadia NM, Hunt KJ, Lopes-Virella MF, Michael Tucker J, Mataria MR, Alge JL, Veterans Affairs Diabetes Trial (VADT) study group. Urine haptoglobin levels predict early renal functional decline in patients with type 2 diabetes. Kidney Int 2013; 83: 1136-1143.

14. Cruz DN, Goh CY, Haase-Fielitz A, Ronco C, Haase M. Early biomarkers of renal injury. Congest Heart Fail 2010; 16: 25-31.

15. Shaker YM, Soliman HA, Ezzat E. Serum and urinary transforming growth factor beta 1 as a biochemical marker in diabetic nephropathy. BJBAS 2014; 3: 16-23.

16. Yaqiu J, Guoliang L, Wei K. Serum level of transforming growth factor-b and its meaning in diabetic nephropathy. J China Med Univ 2001; 30: 125-132.

17. Ibrahim S, Rashed L. Estimation of transforming growth factor-beta 1 as a marker of renal injury in type II diabetes mellitus. Saudi Med J 2007; 28: 519-523.

18. Issani J, Vijayalakshmy R. Role of duration of diabetes in development of nephropathy in type 2 diabetic patients. Nat J Med Res 2013; 3: 5-8.

19. Alrawahi AH, Rizvi SG, Al-Riyami D, Al-Anqoodi Z. Prevalence and risk factors of diabetic nephropathy in omani type 2 diabetics in Al-dakhiliyah region. Oman Med J 2012; 27: 212-216.

20. Hellmich B, Schellner M, Schatz H, Pfeiffer A. Activation of transforming growth factor-betal in diabetic kidney disease. Metabolism 2000; 49: 353-359.

\section{*Correspondence to}

Pawan Kumar Kare

Department of Biochemistry

University College of Medical Sciences and Guru Teg Bahadur Hospital

India 